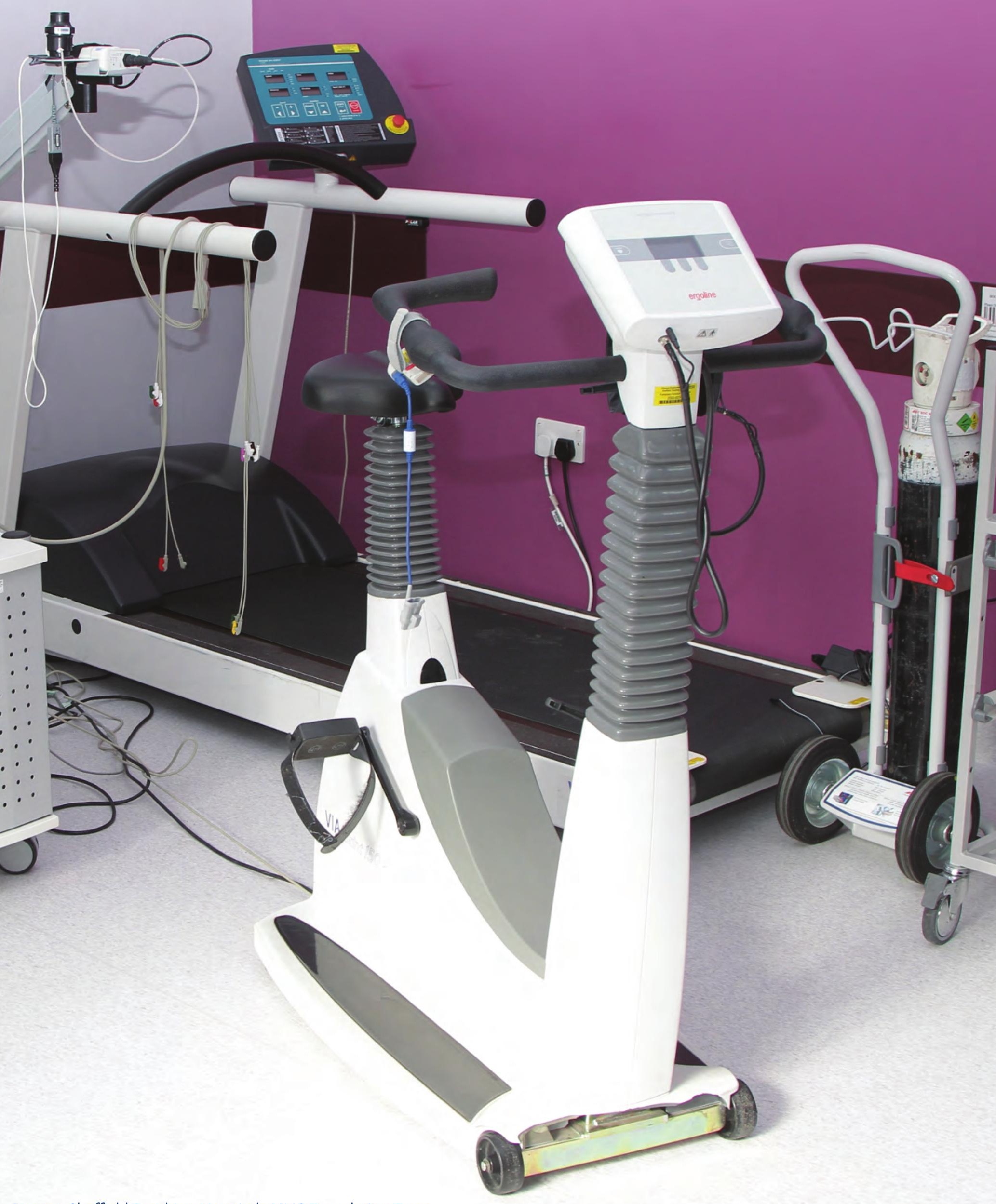




\begin{tabular}{lll}
\hline & & \\
Fabio Pitta, Sharon Mitchell, & For affiliations, please see & Sharon Mitchell, 4 Avenue \\
Michelle Chatwin, Enrico Clini, & the end of the article & Ste-Luce, CH 1003 Lausanne, \\
Margareta Emtner, Rik Gosselink, & & Switzerland \\
Kathleen Grant, Deniz Inal-Ince, & & \\
$\begin{array}{l}\text { Agnieszka Lewko, Beatrice Oberwaldner, } \\
\text { Johanna Williams, Thierry Troosters }\end{array}$ & &
\end{tabular}

\section{A core syllabus for post- graduate training in respiratory physiotherapy}

Physiotherapy contributes significantly to improving quality of life for patients with respiratory disease [1, 2]. Physiotherapists specialised in dealing with respiratory pathology and its associated problems are not only central in the delivery of pulmonary rehabilitation but also provide strategies and techniques for exercise testing, airway clearance, breathlessness management, mobility and function improvement and pain management [2]. Published evidence-based recommendations have paved the way for standardised practice [1-6] while also unravelling the extended scope of responsibilities of the respiratory physiotherapist [7].

The breakdown of traditional roles and allocation of new responsibilities is not confined to the respiratory physiotherapist within healthcare systems. Team-based healthcare and interprofessional treatment of patients is prevalent in the provision of care across the globe. New methods of healthcare delivery indicate that tasks are entrusted to those deemed competent to perform them [8]. It has therefore been necessary to train allied health professionals to take over parts of clinical care [9].

Mobility of the healthcare workforce has been at the forefront of discussion among healthcare providers and policy makers [10].
We now live in a "global village" [11], the consequence of which has seen a marked increase in health professionals completing part of their training and work experience abroad [10]. In this transition to international healthcare, more and more institutions, countries and regions will need standards to meet public, patient and healthcare provider expectations.

This reform in medical practice is thus motivated by the breakdown of traditional roles and responsibilities within the healthcare system [12], increasing trends towards mobility [13] and more complex patient needs. These motivators for change have emphasised a new reality for healthcare systems bounded by a skilled healthcare workforce [14]. In a conference report published by the World Federation of Medical Education (WFME) in 2003 it was stated that "linking education to standards [...] is an important factor in the drive to endure that medical education meets the demand of high quality care" [15]. Today, medical education is operating within a competency-based framework with a focus on outcomes. In other words, what knowledge, skills, and attitudes are required of healthcare professionals on entry into practice and for maintenance of professional practice during their career?
Statement of Interest Sharon Mitchell is an employee of ERS 


\section{Harmonised Education in Respiratory Medicine for European Specialties}

Defining standards in medical education has the potential to harmonise practice in the provision of healthcare, encourage medical education leaders to benchmark against other existing systems and make plans for improvement. It creates a process for assessment and recognition which ensures the medical professional is equipped to enhance patient healthcare [15]. Within the European Union, to a certain degree, standards for graduate medical training have been addressed by the Tuning project and the MEDINE Thematic Network [16]. With regards to international standards for training in physiotherapy some efforts have been made within this domain by the World Confederation of Physical Therapy with the publication of the European Core Standards of Physiotherapy Practice [17] in 2002. Reform within postgraduate training of medical professionals has gained attention across the individual specialties at the European level. The European Society of Cardiology, the European Board of Urology and the European Society of Anaesthesiology, have all embarked on establishing standards for competency-based training within postgraduate specialty areas for both the medical practitioner and allied health professionals.

In 2005, the European Respiratory Society (ERS) followed this trend and began the HERMES (Harmonising Education in

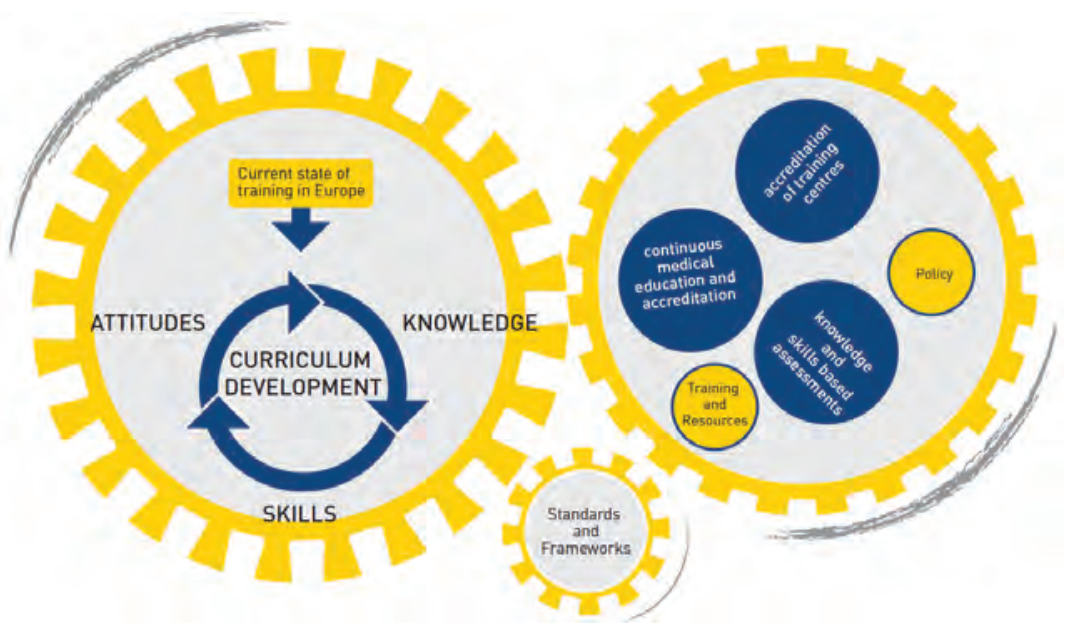

Figure 1

The HERMES model
Table 1 Core components in structure, process and outcome of medical education from defined by the WFME [15]

Mission and objectives
Education programme
Assessment of students
Students
Academic staff/faculty
Education resources
Programme evaluation
Governance and administration
Continuous renewal

Respiratory Medicine for European Specialties) programme to prepare the competent medical practitioner for practice within respiratory medicine specialties. Since its introduction, nine projects have been launched: Adult, Paediatric, Spirometry, Critical care, Sleep, Thoracic oncology, Physiotherapy, Thoracic surgery and Respiratory infections. Establishing standards within medical education is complex and requires consideration for design, planning and implementation on all levels of the educational process. ERS has developed a HERMES model covering each of the key components (fig. 1) as defined by WFME within the framework of medical education (table 1) [15]. During the ERS medical education seminar on 9-10 May 2014, ERS educational leaders came together with key figures in medical education from Canada, the UK and the Netherlands to discuss best practices in medical education and how to challenge HERMES to improve processes and methodology [18]. In 2006, the European Parliament of the European Union published directive 1720/2006/EC to establish an action programme in the field of lifelong learning [19]. As the very essence of HERMES looks to harmonise education across the learning spectrum, a new phase of development focused on continued education and accreditation has been included.

\section{Respiratory Physiotherapy HERMES Task Force: project development}

Within the HERMES educational model, the preliminary phase is designed as part of the curriculum development to address 


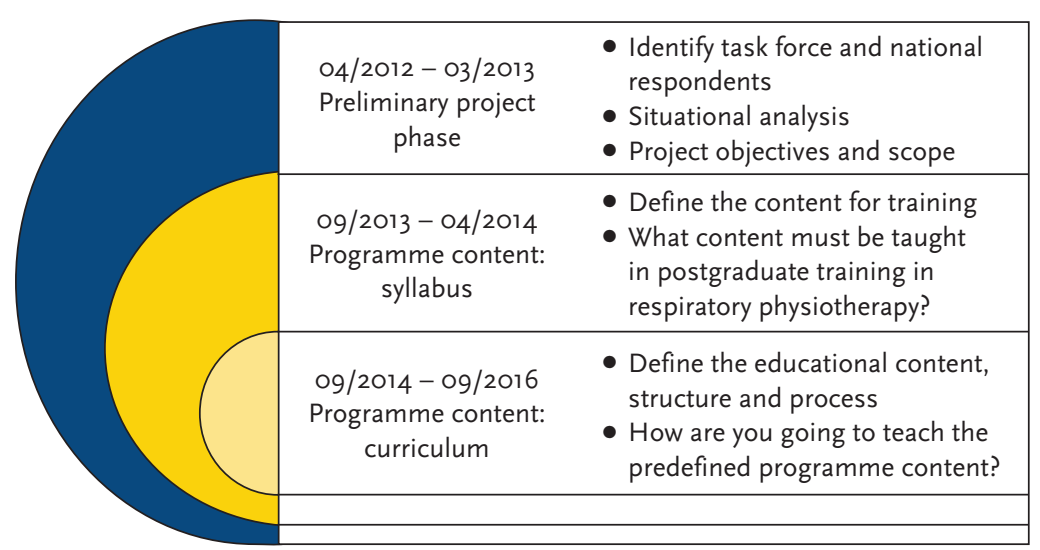

Figure 2

Curriculum content development

important questions around acceptance and applicability of the end product. Once these questions have been addressed, the curriculum then moves towards syllabus design and planning (fig. 2). Curriculum development is a continuous and dynamic process whereby evaluation and monitoring is the final link within the development chain (fig. 3) [20].

\section{Situational analysis}

Societal and political changes which have impacted on healthcare delivery have conscripted leaders to reorganise medical education to provide an expected quality of care to patients. This educational redesign applies to both undergraduate and postgraduate medical training. Further emphasis on the need for change within respiratory physiotherapy was illustrated within a situational analysis conducted by the ERS to evaluate educational delivery within and beyond European borders. Results of this report published in Breathe in March 2013 highlight stark differences in training (ranging from professional bachelor degree level to academic master level and PhD) and assessment practices across countries, but also regional differences within countries [21], thus confirming the need for European standards. At the same time, this observation raises concerns around the entry level of such a harmonisation effort. We have opted to be rather inclusive in our approach but, as a consequence, much of the proposed curriculum may be part of "standard" physiotherapy training in many countries.

\section{Collaborators to the project and objectives}

In September 2011, the respiratory physiotherapy task force, representing nine countries (fig. 4) as well as key physiotherapy societies and groups, gathered for their first meeting to discuss and define the project objectives and mission grounded within the HERMES model.

Prior to preparation of the programme content, the taskforce sought to reach consensus on their overall objective; to equip respiratory physiotherapists with the knowledge, skills and attitudes required for practice,

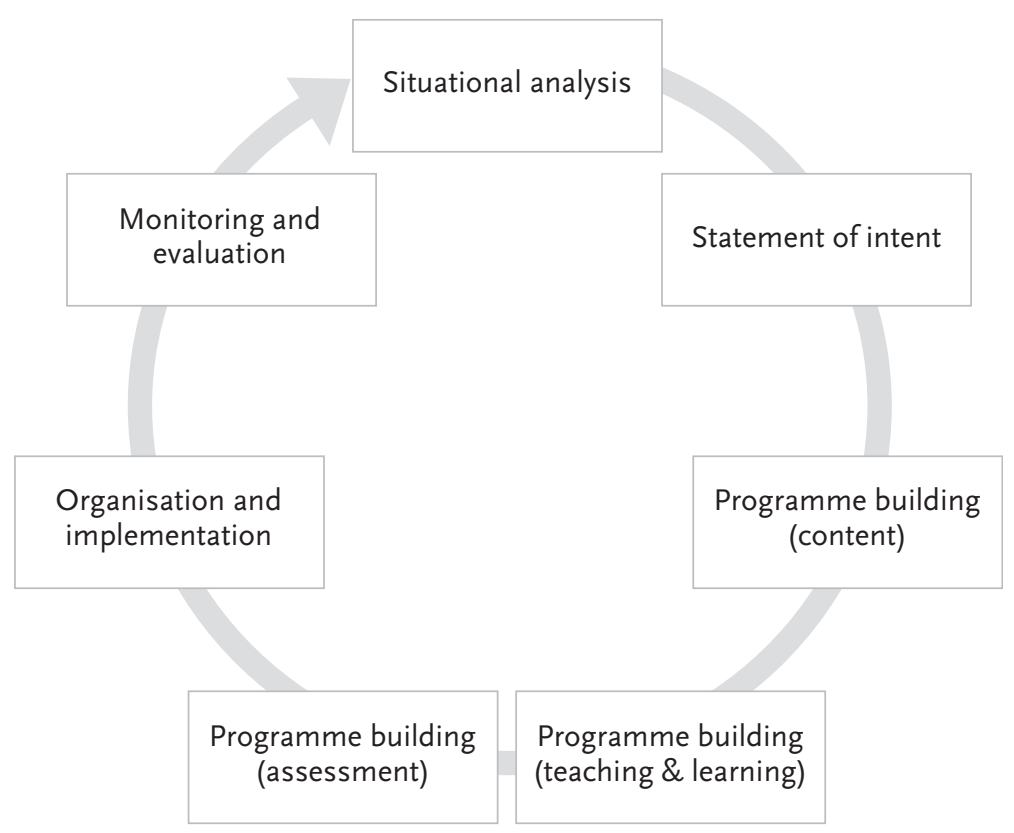

Figure 3

The situational analysis model emphasises the importance of context in curriculum design. Reproduced from [20] with permission from the publisher. 


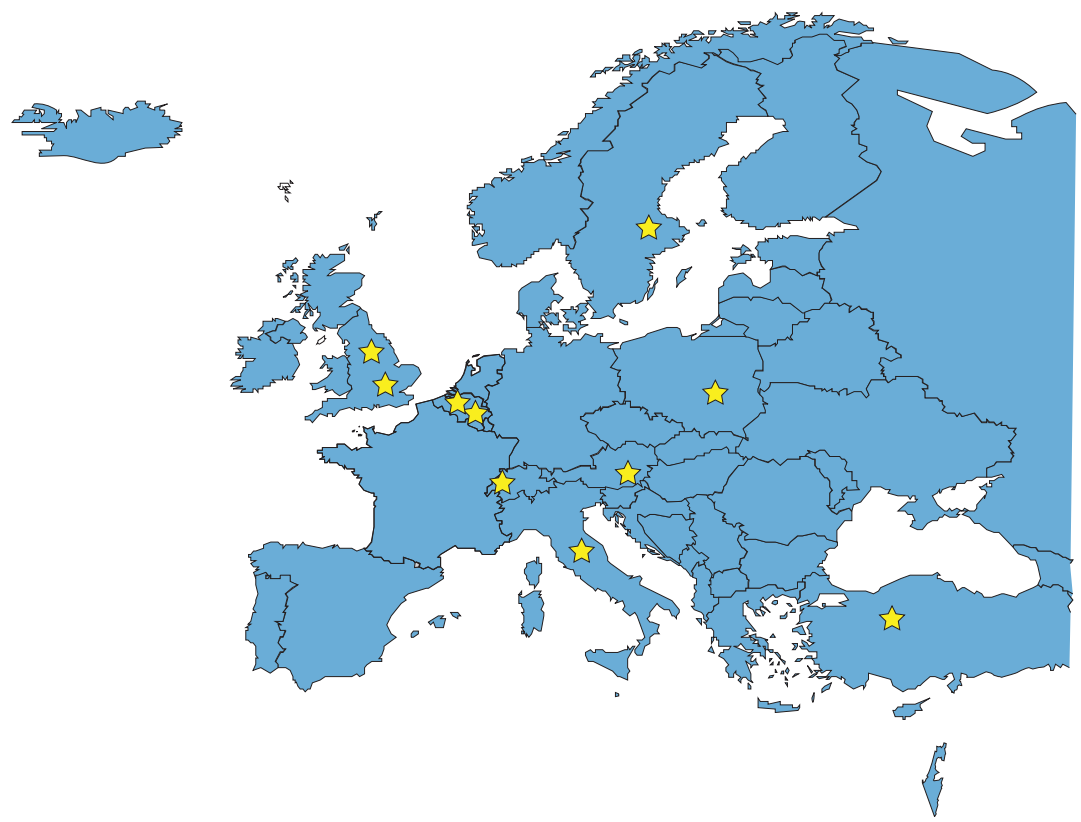

Figure 4

Countries represented by the Respiratory Physiotherapy HERMES task force. One task force member is based in Brazil. continues to be widely used as a valuable tool to establish guidelines, standards, policy documents and for predicting trends [24, 25]. Typically, the Delphi process comprises of a series of three rounds to 1) present the information and allow respondents the flexibility to elaborate on the content and make suggestions; 2) feed results back and present more specific information and 3) feed results back and give the respondent the opportunity to comment on why their opinion remains outside the consensus.

To apply the Delphi technique to the aims and objectives of creating standards for training content in postgraduate respiratory physiotherapy, three broad elements were considered in the design and presentation of this process:

1. Nomination of the expert panel and number of experts to be included: the Task Force reviewed a draft list of knowledge and skills items for review and made final preparations for the first Delphi Round. For this project, it was decided to focus on the dedicated group of experts including task force members and national experts to the project selected by nomination. This process reflects best practices stated within the literature that principal investigators should select the most appropriate individuals through an appointment process [25]. The Task Force also identified the ERS Assembly group 9.02 physiotherapists as a further expert panel to be included. The optimal number of respondents to include within a Delphi process is debated extensively within published research [23, 25]. However, it is noted that the Delphi process does not require representative samples, but representativeness is assessed on the qualities of the assigned group [23].

2. Assigned level of consensus: within this task force it was decided to employ a consensus of $80 \%$. This judgement was made based on two determining factors 1) recommendations within the literature $[22,25]$ and 2) the high level of consensus across items presented in the first Delphi round. There is generally no confirmed agreement on the level of consensus for expert groups [25] rather that consistency of responses across each of the Delphi rounds is a better predictor of consensus [22]. Within the HERMES model, consensus rates have been between $70 \%$ and $80 \%$.

3. Modified Delphi Approach: although the Delphi technique typically begins as a 
qualitative study, the presentation of a more structured questionnaire during this first round is also accepted if basic information concerning the target issue is available and useable [25]. Within this Delphi model, individual feedback is not offered to each of the experts, as is proposed in the literature [24]. If module items reached consensus of $>80 \%$, the items were not re-presented in the subsequent rounds and the consensus results were displayed in a survey table. General feedback on each survey round was also presented within the survey introduction so that participants understood task force decisions based on Delphi results taken during the meetings.

\section{Results}

Timelines and actions of the Delphi questionnaire series can be found in figure 5 (more detailed results may be found on the ERS HERMES website under the physiotherapy HERMES project). As there are two task force meetings that take place annually in September and April, results of each of the surveys were discussed and deliberated during the meetings dictating the organisation and planning for the questionnaire design and delivery.

\section{Design and organisation of the Delphi rounds}

\section{Delphi round 1}

The field of respiratory physiotherapy is very broad ranging from newborn to adult patients with stable or unstable disease requiring intensive care treatments. There is little overlap in professionals covering all these diverse areas. It was therefore decided that a modular approach would be followed. The first Delphi round presented 10 modules, two of which specifically addressed newborn and infant patients, and eight which the task force felt were common to both adult and paediatric modules.

Within this round, the task force also sought expert opinion on the inclusion of research and communication modules. Additionally, suggestions for content for these modules were also sought. 90\% of respondents believed that a module on research should be included and $87 \%$ of respondents thought that a module on communication should be part of postgraduate training content in respiratory physiotherapy.

\section{Delphi rounds 2 and 3}

Full modules and module items were presented in Delphi rounds 2 and 3 for research, teaching and communications. Feedback within the first round also assisted the task force to remodel the syllabus into two separate tracks to cover adult and paediatric respiratory physiotherapy training and assessment. The subsequent survey rounds were then divided into two training tracks for adult and paediatric.

Overall the survey sought to gain $>80 \%$ consensus on whether the presented modules should be included within an international training programme in respiratory physiotherapy, and the module items presented should be mandatory or optional.

For Delphi round 2 and 3, the survey was first sent out to the task force expert group to provide their comments for improvement before sending to national experts and Assembly 9.02 (respiratory physiotherapy) members.

\section{Syllabus}

The content for a training programme in respiratory physiotherapy was approved during the task force meeting in April 2014. The final Delphi round yielded high consensus rates across the adult and paediatric modules with only 7 (5\%) of 133 items not reaching consensus. Of the 10 module items presented within the communication and education modules and the research skills module, four reached consensus of $>80 \%$, two items were eliminated, three items will feature in the curriculum and one item was reworded.

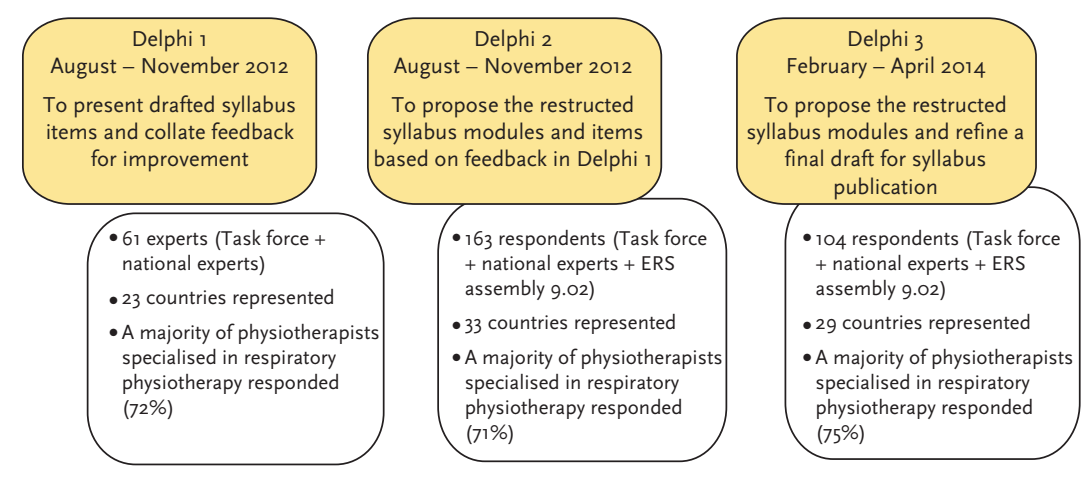

Figure 5

Overview of the Delphi process 
The complete syllabus can be found online at http://ow.ly/zYkOD

\section{Discussion}

\section{Modular training programmes}

With the decision to divide training into two individual educational programmes for adult and paediatric respiratory physiotherapy, the task force considered how such training could be implemented. Modular training is not new to education and offers learners the opportunity to take part in special study modules and higher-level competencies [26]. For each module presented in the syllabus, experts were requested to propose whether these modules should be mandatory or optional, thus offering learners the opportunity to master the core modules and to include additional modules depending on the knowledge, skills and attitudes required within their field of work. The educational programmes for adult and paediatric training in respiratory physiotherapy will be based on a modular programme of core and optional modules. For those interested in completing both adult and paediatric training tracks, exemptions may be considered during the curriculum development where substantial overlaps occur across both training programmes.

\section{Representativeness}

The situational analysis to some extent sketches a blueprint of respiratory physiotherapy practice across countries defining who within the multidisciplinary team is responsible for specific tasks. What is difficult to deduce from these findings is the true representation of respiratory physiotherapy practice globally. How many countries recognise respiratory physiotherapy as a specialty area? How many respiratory physiotherapists exist worldwide? How many physiotherapists with a special interest in the "respiratory" field are practicing internationally?

Reverting back to the literature on sample size of surveys, representativeness is debated extensively. It is noted that what constitutes the appropriate number should consider the overall representation of the expert pool [25]. Other studies have argued that there is no empirical evidence of the impact of the number of participants on the reliability and validity of consensus processes [23]. As responding participants from the Delphi series are drawn largely from ERS databases and constitute a sample of highly trained professionals, there is concern that this may lead to an ambitious curriculum benefiting those subscribing to it in the future. Without conducting further research in this area, it is impossible to ascertain the true number of practicing respiratory physiotherapists internationally. In addition it is unclear how many physiotherapists are trained as general physiotherapists working with respiratory patients and how many are specialised physiotherapists in the respiratory field. The task force may consider future research in this area.

\section{Applicability and acceptability}

Standardising education at international level is a complex process that requires consideration and reform in the planning, design and implementation of an educational programme. Widening the scope of practice for allied health professionals is central to current changes taking place within postgraduate medical education and practice, and studies reveal that this is also true for the practice of respiratory physiotherapy [7]. International curriculum design within this field of practice requires consideration of the global competencies expected of the respiratory physiotherapist and what the respiratory physiotherapist is legally permitted to perform in a specific country or even region. In other words, to strike a balance between acceptability and applicability of the educational programme. A harmonised curriculum could be a first step to also standardise the actions that can legally be performed by a physiotherapist. This however is a political process whereby educational guidance can only serve as a potential facilitator.

\section{Conclusion}

The benefits of establishing a universal agreement for postgraduate training for the respiratory physiotherapist specialist are real and significant. The heterogeneity of the graduate-level education imposes an additional challenge. Standardised education has the potential to disseminate the competencies 
required of the specialist and to create a framework for national legislation and governance. More specifically, fixed standards for training, assessment, accreditation and institutional accreditation, as well as standardised resources have the potential to safeguard practice, ensure quality care, while also addressing the pace of change impacting health care delivery. The HERMES model, founded on competency-based education, provides a platform from which to design and build an educational programme for the respiratory physiotherapist. The task force will now move forward with the development of a complete curriculum stipulating the knowledge, skills, attitudes, expected levels of competence, assessment and educational activities required for standardised training. Once the curriculum has been published, following the framework of the HERMES model, activities including assessments, accreditation of training institutions and continued professional development for the trained respiratory physiotherapist will be designed and implemented where possible. With the intended purpose of training the respiratory physiotherapist to perform competently, it is hoped that the presented challenges will be overcome to secure quality international care for respiratory disease patients.

Author affiliations are as follows: Fabio Pitta: Laboratorio de Pesquisa em Fisioterapia Pulmonar, Departamento de Fisioterapia, Universidade Estadual de Londrina, Londrina, Brazil; Sharon Mitchell: ERS Headquarters, Lausanne, Switzerland; Michelle Chatwin: Dept of Sleep and Ventilation, Royal Brompton Hospital, London, UK; Enrico Clini: Dept of Medical and Surgical Sciences, University of Modena and Ospedale Villa Pineta, Modena, Italy; Margareta Emtner: Dept of Neuroscience, Physiotherapy, University of Uppsala, Uppsala, Sweden; Rik Gosselink: Division of Respiratory Rehabilitation, University Hospital Gasthuisberg, Leuven, Belgium; Kathleen Grant: Department of Physiotherapy, Centre Hospitalier Universitaire Vaudois (CHUV), Lausanne, Switzerland; Deniz Inal-Ince: Department of Physiotherapy and Rehabilitation, Faculty of Health Sciences, Hacettepe University, Ankara, Turkey; Agnieszka Lewko: Faculty of Health, Social Care and Education, St. George's University of London and Kingston University, UK; Beatrice Oberwaldner: Respiratory and Allergic Disease Division, Paediatric Department, Medical University of Graz, Graz, Austria; Johanna Williams: Centre for Exercise and Rehabilitation Science, Glenfield Hospital, University Hospitals of Leicester NHS Trust, Leicester, UK; Thierry Troosters: Dept of Rehabilitation Sciences, University of Leuven, Leuven, Belgium.

\section{References}

1. Garrod R, Lasserson T. Role of physiotherapy in the management of chronic lung diseases. Respir Med 2007; 101: 2429-2436.

2. Bott J, Blumenthal S, Buxton M, et al. Guidelines for the physiotherapy management of the adult, medical, spontaneously breathing patient. Thorax 2009; 64: i1-i51.

3. Langer D, Hendriks E, Burtin C, et al. A clinical practice guideline for physiotherapists treating patients with chronic obstructive pulmonary disease based on a systematic review of available evidence. Clin Rehabil 2009; 23: 445-462.

4. Stiller K. Physiotherapy in intensive care: an updated systematic review. Chest 2013; 144: 825-847.

5. Gosselink R, Bott J, Johnson M, et al. Physiotherapy for adult patients with critical illness: recommendations of the European Respiratory Society of Intensive Care Medicine Task Force on Physiotherapy for Critically III Patients. Intensive Care Med 2008; 34: 1188-1199.
6. Clini E, Ambrosino N. Early physiotherapy in the respiratory intensive care unit. Respir Med 2005; 99: 1096-1104.

7. Kersten P, McPherson, Lattimer $V$, et al. Physiotherapy extended scope of practice - who is doing what and why? Physiotherapy 2007; 93: 235-242.

8. Ten Cate OT, Snell L, Carraccio C. Medical competence: the interplay between individual ability and the health care environment. Medical Teacher 2010; 32: 669-675.

9. Mulder H, Cate OT, Daalder R, et al. Building a competency-based workplace curriculum around entrustable professional activities: The case of physician assistant training. Medical Teacher 2010; 32: e453-e459.

10. Wismar M, Glinos I, Maier C, et al. Health professional mobility and health systems: evidence from 17 European countries. Euro Observer 2011; 13: $1-4$. 
11. Swartz R.M., Globalization and medical education. Medical Teacher 2001; 23; 533-534.

12. Gukas I. Global paradigm shift in medical education: issues of concern for Africa. Medical teacher 2007; 29: 887-892.

13. Lilley P, Harden R. Standards and medical education. Medical Teacher 2003; 25: 349-351.

14. Buchan J, Dal Poz MR. Skill mix in the health care workforce: reviewing the evidence. Bulletin of the World Health Organisation 2002; 80. Available from www.who.int/hrh/documents/skill_mix.pdf Date last accessed: 10 June 2014.

15. Van Niekerk J, Christensen L, Karle $\mathrm{H}$, et al. WFME Global Standards in Medical Education: status and perspectives following the 2003 WFME World Conference. Medical Education 2003; 37: 1050-1054.

16. Tuning Educational Structures in Europe. www. unideusto.org/tuningeu Date last accessed: 11 June 2014

17. World confederation of Physical Therapy. European core standards for physiotherapy practice. Adopted final version. 9 November 2011. www. physio-europe. org/download. php?document $=71 \&$ downloadarea $=6$. Date last accessed: 11 June 2014.

18. Mitchell S, Bloch KE, Butienne I, et al. "Education is the passport to the future": enabling today's medical teachers to prepare tomorrow's respiratory health practitioners'. Eur Respir J 2014; 44: 578-584.
19. Decision No $1720 / 2006$ of the European Parliament and of the council of 15 November 2006 establishing an action programme in the field of lifelong learning. Official Journal of the European Union. 24.11.2006. http://eur-lex.europa.eu/LexUriServ/LexUriServ.do?uri= OJ:L:2006:327:0045:0068:en:PDF. Date last accessed: 11 June 2014

20. Prideaux $D$. $A B C$ of learning and teaching in medicine: curriculum design. $\mathrm{Br}$ Med J 2003; 326: 268.

21. Mitchell S, Pitta F, Troosters T. Standardised education and training for respiratory physiotherapists. Breathe 2013; 9: $171-174$

22. Hasson F, Keeney S, McKenna H. Research guidelines for the Delphi survey technique. J Adv Nurs 2000; 32: 1008-1015.

23. Powell $C$. The Delphi technique: myths and realities. J Adv Nurs 2002; 41: 376-382.

24. Green RA. The Delphi technique in educational research. SAGE Journals Open. April-June 2014: 1-8. http://sgo.sagepub.com/content/4/2/ 2158244014529773 Date last accessed: 11 June 2014

25. Hsu CC, \& Stanford BA. The Delphi Technique: Making Sense of Consensus. Practical Assessment Research Q Evaluation. 2007. 12(10). http://sgo.sagepub.com/ content/4/2/2158244014529773. Date last accessed: 11 June 2014.

26. Harden RM, Davis MH. AMEE Medical Education Guide No.5. The core curriculum with options or special study modules 1995; 17: 125-148. 